University of Nebraska - Lincoln

DigitalCommons@University of Nebraska - Lincoln

2010

Retrofit of Distillation Columns in Biodiesel Production Plants

Nghi Nguyen

University of Nebraska - Lincoln

Yaşar Demirel

University of Nebraska - Lincoln, ydemirel2@unl.edu

Follow this and additional works at: https://digitalcommons.unl.edu/cbmedemirel

Part of the Chemical Engineering Commons

Nguyen, Nghi and Demirel, Yaşar, "Retrofit of Distillation Columns in Biodiesel Production Plants" (2010). Yasar Demirel Publications. 6.

https://digitalcommons.unl.edu/cbmedemirel/6

This Article is brought to you for free and open access by the Chemical and Biomolecular Research Papers -- Faculty Authors Series at DigitalCommons@University of Nebraska - Lincoln. It has been accepted for inclusion in Yasar Demirel Publications by an authorized administrator of DigitalCommons@University of Nebraska - Lincoln. 


\title{
Retrofit of Distillation Columns in Biodiesel Production Plants
}

\author{
Nghi Nguyen, Yaşar Demirel
}

\author{
Department of Chemical and Biomolecular Engineering, University of Nebraska-Lincoln, \\ Lincoln, Nebraska, U.S.A. \\ Corresponding author, Demirel: ydemirel2@unl.edu
}

Article history: Received June 30, 2009; received in revised form December 5, 2009; accepted December 8, 2009; available online December 31, 2009; authors' version uploaded to the University of Nebraska-Lincoln institutional repository, June 6, 2012.

Keywords: Thermodynamic analysis, Column grand composite curves, Exergy loss, Retrofitting, Thermodynamic efficiency

\begin{abstract}
Column grand composite curves and the exergy loss profiles produced by the Column-Targeting Tool of the Aspen Plus simulator are used to assess the performance of the existing distillation columns, and reduce the costs of operation by appropriate retrofits in a biodiesel production plant. Effectiveness of the retrofits is assessed by means of thermodynamics and economic improvements. We have considered a biodiesel plant utilizing three distillation columns to purify biodiesel (fatty acid methyl ester) and byproduct glycerol as well as reduce the waste. The assessments of the base case simulation have indicated the need for modifications for the distillation columns. For column T202, the retrofits consisting of a feed preheating and reflux ratio modification have reduced the total exergy loss by 47\%, while T301 and T302 columns exergy losses decreased by $61 \%$ and 52\%, respectively. After the retrofits, the overall exergy loss for the three columns has decreased from $7491.86 \mathrm{~kW}$ to $3627.97 \mathrm{~kW}$. The retrofits required a fixed capital cost of approximately $\$ 239,900$ and saved approximately $\$ 1,900,000 /$ year worth of electricity. The retrofits have reduced the consumption of energy considerably, and leaded to a more environmentally-friendly operation for the biodiesel plant considered.
\end{abstract}

\section{Introduction}

Separation by distillation is energy-intensive process. Operations in four different continuous biodiesel plants show that the cost of separation by distillation varies from $7 \%$ to $22 \%$ of the total manufacturing cost [1] and the methanol separation accounts around $66 \%$ of it [2]. Retrofits suggest modifications for existing distillation columns to reduce the costs of operations by increasing the efficiency in energy utilization [3-5]. Thermodynamic Analysis is one of the methods for retrofitting by reducing the thermodynamic losses due to heat and mass transfer, pressure drop, and mixing $[4,6]$. The Aspen Plus simulator performs the thermodynamic analysis through its Column-Targeting Tool for rigorous column calculations [7]. Column grand composite curves (CGCC) and the exergy loss profiles produced by the Column-Targeting Tool are used to retrofit the existing distillation columns in a biodiesel production plant. CGCCs and stage-exergy loss profiles are becoming readily available [7] even for multicomponent, complex distillation column operations such as crude oil distillation $[8,9]$. This enables the process engineer to assess an existing operation, and suggest suitable retrofits for reducing utility costs by improving efficiency in energy usage $[10,11]$.

\section{Thermodynamic Analysis}

An entropy effect leading to energy dissipation or exer- gy loss either within or through the boundary of a system is unavoidable in every irreversible system. Thermodynamic analysis determines the net enthalpy deficits and exergy losses due to irreversibility at each stage of a distillation column by combining the first and second laws of thermodynamics. The distributions of the enthalpy deficits and exergy losses identify the scope and extent of retrofits for improvements by reducing the irreversibility [10-17] and/or distributing them evenly [15]. Effectiveness of retrofits is determined after overall optimization, which seeks improvement for the conventional plant under specific constraints. Therefore, the relations between the energy efficiency and capital cost must be evaluated [18].

The Column-Targeting tool of Aspen Plus performs thermal analysis to produce the CGCC and the exergy loss profiles for rigorous column calculations based on the Pactical Near-Minimum Thermodynamic Condition (PNMTC). Enthalpy deficit curves are available as stage-enthalpy (Stage$\mathrm{H})$ and temperature-enthalpy $(\mathrm{T}-\mathrm{H})$ profiles. These profiles represent the cumulative heating and cooling requirements for the column to operate at PNMTC. This approximation takes into account the losses or inefficiencies introduced through pressure drops, mixing, and heat and mass transfer. A part of accessible work potential is always lost in any real process. Exergy $\left(E_{x}\right)$ is the accessible work potential and defines the maximum amount of work that may be per- 
formed theoretically by bringing a resource into equilibrium with its surrounding through a reversible process. Molar exergy $e_{x}$ is defined by

$e_{x}=\Delta h-T_{0} \Delta s=\left(h-h_{0}\right)-T_{0}\left(s-s_{0}\right)$

where $h$ is the molar enthalpy, $s$ is the molar entropy, and $T_{0}$ is the reference temperature, which is usually assumed as the environmental temperature of $25.0^{\circ} \mathrm{C}$. Exergy is a function of both the physical properties of a resource and its environment. Exergy Loss profiles are available as stage-exergy loss and temperature-exergy loss profiles, and measure their reversibility in the column due to momentum loss (pressuredriving force), thermal loss (temperature-driving force/ mixing), and chemical-potential loss (mass transfer driving force/mixing). These profiles can be used as a tool to examine the degradation of accessible work for all the internal trays of the column.

\subsection{Column Grand Composite Curve (CGCC)}

The CGCC displays the net enthalpies for the actual and ideal operations at each stage, and theoretical minimum cooling and heating requirements in the temperature range of separation. The area between the actual and the ideal operations in a CGCC should be small. The CGCCs help in identifying the following retrofits: (i) feed location (appropriate placement), (ii) reflux ratio (reflux ratio vs. number of stages), (iii) feed conditioning (heating or cooling), and (iv) side condensing and reboiling. A sharp enthalpy change occurring on the Stage-HCGCC on the condenser side indicates that a feed has been introduced too high up in the column and should be moved down. Similarly, a feed introduced too low in the column will cause a sharp enthalpy change on the Stage-HCGCC on the reboiler side and should be moved up. Appropriate feed placement removes the distortions in the Stage-HCGCC but also reduces the condenser or reboiler duty. Reflux ratio reduction lowers the condenser and re-
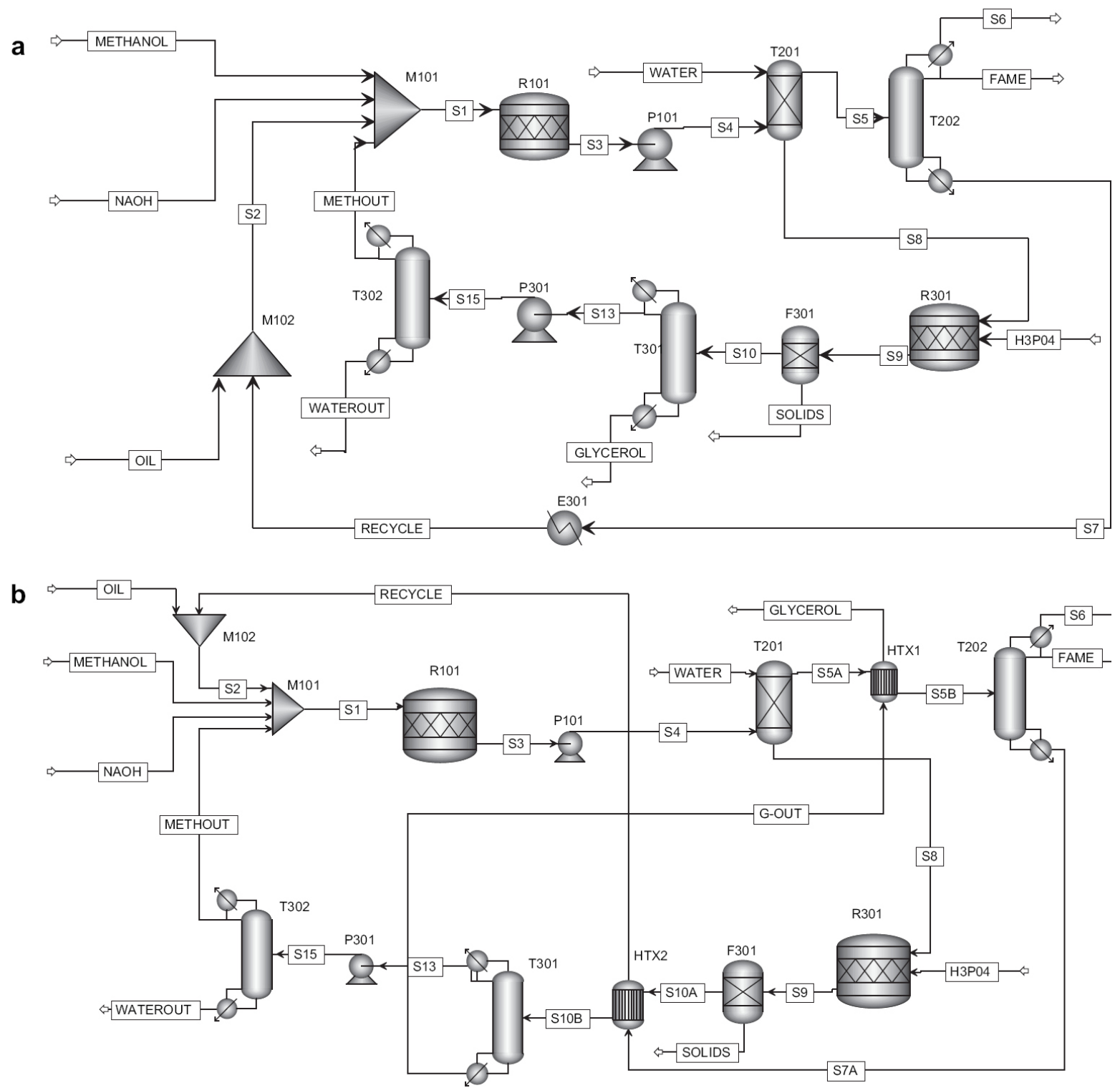

Figure 1. Flow diagram for biodiesel plant: (a) base case design; (b) retrofitted design. 
Table 1

Streams properties of the base case design of biodiesel production plant.

\begin{tabular}{|c|c|c|c|c|c|c|c|}
\hline & Fame & Glycerol & Methanol & Methout & Oil & Water & Waterout \\
\hline Temperature ${ }^{\circ} \mathrm{C}$ & $4.40 \mathrm{E}+01$ & $2.55 \mathrm{E}+02$ & $2.50 \mathrm{E}+01$ & $6.68 \mathrm{E}+01$ & $2.50 \mathrm{E}+01$ & $2.50 \mathrm{E}+01$ & $1.02 \mathrm{E}+02$ \\
\hline Pressurebar & $1.00 \mathrm{E}-01$ & $5.00 \mathrm{E}-01$ & $1.00 \mathrm{E}+00$ & $1.10 \mathrm{E}+00$ & $1.00 \mathrm{E}+00$ & $1.10 \mathrm{E}+00$ & $1.10 \mathrm{E}+00$ \\
\hline Vapor Frac & $0.00 \mathrm{E}+00$ & $0.00 \mathrm{E}+00$ & $0.00 \mathrm{E}+00$ & $0.00 \mathrm{E}+00$ & $0.00 \mathrm{E}+00$ & $0.00 \mathrm{E}+00$ & $0.00 \mathrm{E}+00$ \\
\hline Mass Flow kg/h & $2.44 \mathrm{E}+04$ & $2.51 \mathrm{E}+03$ & $2.73 E+03$ & $2.91 E+03$ & $2.41 \mathrm{E}+04$ & $5.50 \mathrm{E}+02$ & $2.40 \mathrm{E}+03$ \\
\hline $\begin{array}{l}\text { Enthalpy MMBtu/h } \\
\text { Mass Flow } \mathrm{kg} / \mathrm{h}\end{array}$ & $5.66 \mathrm{E}+01$ & $1.60 \mathrm{E}+01$ & $1.94 \mathrm{E}+01$ & $2.02 \mathrm{E}+01$ & $5.66 \mathrm{E}+01$ & $8.27 \mathrm{E}+00$ & $3.53 \mathrm{E}+01$ \\
\hline METHANOL & $5.42 \mathrm{E}+01$ & 7.52E-01 & $2.73 E+03$ & $2.91 \mathrm{E}+03$ & $0.00 \mathrm{E}+00$ & $0.00 \mathrm{E}+00$ & $8.45 \mathrm{E}+00$ \\
\hline OIL & $3.96 \mathrm{E}+01$ & $0.00 \mathrm{E}+00$ & $0.00 \mathrm{E}+00$ & $0.00 \mathrm{E}+00$ & $2.41 \mathrm{E}+04$ & $0.00 \mathrm{E}+00$ & $0.00 \mathrm{E}+00$ \\
\hline FAME & $2.42 E+04$ & 5.73E-04 & $0.00 \mathrm{E}+00$ & $1.11 \mathrm{E}-66$ & $0.00 \mathrm{E}+00$ & $0.00 \mathrm{E}+00$ & 8.36E-01 \\
\hline GLYCEROL & $1.43 \mathrm{E}-08$ & $2.51 E+03$ & $0.00 \mathrm{E}+00$ & $5.91 \mathrm{E}-57$ & $0.00 \mathrm{E}+00$ & $0.00 \mathrm{E}+00$ & $4.96 \mathrm{E}-04$ \\
\hline $\mathrm{NAOH}$ & $7.45 \mathrm{E}-04$ & $0.00 \mathrm{E}+00$ & $0.00 \mathrm{E}+00$ & $0.00 \mathrm{E}+00$ & $0.00 \mathrm{E}+00$ & $0.00 \mathrm{E}+00$ & $0.00 \mathrm{E}+00$ \\
\hline WATER & $4.78 \mathrm{E}+01$ & $1.96 \mathrm{E}+00$ & $0.00 \mathrm{E}+00$ & $3.37 \mathrm{E}+00$ & $0.00 \mathrm{E}+00$ & $5.50 \mathrm{E}+02$ & $2.39 E+03$ \\
\hline $\mathrm{H} 3 \mathrm{PO} 4$ & $0.00 \mathrm{E}+00$ & $0.0 \mathrm{E}+00$ & $0.00 \mathrm{E}+00$ & $0.00 \mathrm{E}+00$ & $0.00 \mathrm{E}+00$ & $0.00 \mathrm{E}+00$ & $0.00 \mathrm{E}+00$ \\
\hline NA3PO4 & $0.00 \mathrm{E}+00$ & $0.00 \mathrm{E}+00$ & $0.00 \mathrm{E}+00$ & $0.00 \mathrm{E}+00$ & $0.00 \mathrm{E}+00$ & $0.00 \mathrm{E}+00$ & $0.00 \mathrm{E}+00$ \\
\hline \multicolumn{8}{|l|}{ Mass Frac } \\
\hline METHANOL & $2.22 \mathrm{E}-03$ & $3.00 \mathrm{E}-04$ & $1.00 \mathrm{E}+00$ & 9.99E-01 & $0.00 \mathrm{E}+00$ & $0.00 \mathrm{E}+00$ & 3.51E-03 \\
\hline OIL & $1.62 \mathrm{E}-03$ & $0.00 \mathrm{E}+00$ & $0.00 \mathrm{E}+00$ & $0.00 \mathrm{E}+00$ & $1.00 \mathrm{E}+00$ & $0.00 \mathrm{E}+00$ & $0.00 \mathrm{E}+00$ \\
\hline FAME & $9.94 \mathrm{E}-01$ & $2.28 \mathrm{E}-07$ & $0.00 \mathrm{E}+00$ & $3.81 \mathrm{E}-70$ & $0.00 \mathrm{E}+00$ & $0.00 \mathrm{E}+00$ & $3.48 \mathrm{E}-04$ \\
\hline GLYCEROL & $5.86 \mathrm{E}-13$ & $9.99 \mathrm{E}-01$ & $0.00 \mathrm{E}+00$ & 2.03E-60 & $0.00 \mathrm{E}+00$ & $0.00 \mathrm{E}+00$ & 2.06E-07 \\
\hline $\mathrm{NAOH}$ & $3.06 \mathrm{E}-08$ & $0.00 \mathrm{E}+00$ & $0.00 \mathrm{E}+00$ & $0.00 \mathrm{E}+00$ & $0.00 \mathrm{E}+00$ & $0.00 \mathrm{E}+00$ & $0.00 \mathrm{E}+00$ \\
\hline WATER & $1.96 \mathrm{E}-03$ & 7.82E-04 & $0.00 \mathrm{E}+00$ & $1.16 \mathrm{E}-03$ & $0.00 \mathrm{E}+00$ & $1.00 \mathrm{E}+00$ & 9.96E-01 \\
\hline $\mathrm{H} 3 \mathrm{PO} 4$ & $0.00 \mathrm{E}+00$ & $0.00 \mathrm{E}+00$ & $0.00 \mathrm{E}+00$ & $0.00 \mathrm{E}+00$ & $0.00 \mathrm{E}+00$ & $0.00 \mathrm{E}+00$ & $0.00 \mathrm{E}+00$ \\
\hline NA3PO4 & $0.00 \mathrm{E}+00$ & $0.00 \mathrm{E}+00$ & $0.00 \mathrm{E}+00$ & $0.00 \mathrm{E}+00$ & $0.00 \mathrm{E}+00$ & $0.00 \mathrm{E}+00$ & $0.00 \mathrm{E}+00$ \\
\hline
\end{tabular}

boiler duties, decreases operating costs, however, it will increase the number of stages, increase capital costs, to preserve the separation. User must carefully analyze to determine whether saving in operating costs compensate higher capital costs. Feed preheating or cooling can reduce thermal loss on the feed stage. Using existing heat sources available in the plant are desirable and side condensing or side reboiling provides the column with a cheaper cold or hot utlity [3-7].

Using the equilibrium compositions of light (L) and heavy (H) key components minimum vapor and liquid flow rates leaving the same stage with the same temperatures can be estimated from the following mass balances

$$
\begin{aligned}
& \dot{V}_{\min }=\frac{1}{y_{L}^{*}}\left(\dot{D}_{L}+\dot{L}_{\min } x_{L}^{*}\right) \\
& \dot{L}_{\min }=\frac{1}{x_{H}^{*}}\left(\dot{V}_{\min } y_{H}^{*}-\dot{D}_{H}\right)
\end{aligned}
$$

The enthalpies for the minimum vapor and liquid flows are

Table 2

Comparison of operating conditions and configurations of designs 1 and 2 for distillation column T202.

$\begin{array}{lcc}\text { Conditions \& Configurations } & \text { Design } 1 \text { (base case) } & \text { Design } 2 \text { (retrofitted) } \\ \text { No. of stages } & 6 & 8 \\ \text { Feed stage } & 3 & 3 \\ \text { Feed temperature, }{ }^{\circ} \mathrm{C} & 60.00 & 86.50 \\ \text { Reflux ratio } & 1.10 & 0.19 \\ \text { Condenser duty, } \mathrm{kW} & -10897.10 & -6129.29 \\ \text { Distillate rate, } \mathrm{kmol} / \mathrm{h} & 90.47 & 90.45 \\ \text { Condenser temperature, }{ }^{\circ} \mathrm{C} & 44.01 & 44.08 \\ \text { Condenser pressure, bar } & 0.10 & 0.10 \\ \text { Reboiler duty, } \mathrm{kW} & 10985.16 & 5840.57 \\ \text { Boil up rate, } \mathrm{kmol} / \mathrm{h} & 217.59 & 108.32 \\ \text { Bottoms rate, } \mathrm{kmol} / \mathrm{h} & 1.75 & 1.71 \\ \text { Reboiler temperature, }{ }^{\circ} \mathrm{C} & 340.34 & 347.12 \\ \text { Reboiler pressure, bar } & 0.20 & 0.20\end{array}$

obtained from the molar flow ratios

$$
\begin{aligned}
& H_{V \min }=H_{V}^{*}\left(\frac{\dot{V}_{\min }}{\dot{V}^{*}}\right) \\
& H_{L \min }=H_{L}^{*}\left(\frac{\dot{L}_{\min }}{\dot{L}^{*}}\right)
\end{aligned}
$$

Here $\dot{V}^{*}$ and $\dot{L}^{*}$ are the molar flow rates at equilibrium, and $H_{V}^{*}$ and $H_{L}^{*}$ are enthalpies of vapor and liquid streams leaving the same stage at equilibrium, respectively. From the enthalpy balances at each stage, the net enthalpy deficits are obtained by $[3,13]$

$H_{\text {def }}=H_{L \min }-H_{V \min }+H_{D}$ (before the feed stage)

$H_{\text {def }}=H_{L \min }-H_{V \min }+H_{D}-H_{\text {feed }}$ (after the feed stage)

After adding the individual stage-enthalpy deficits to the condenser duty, the enthalpy values are cascaded, and plotted in the CGCC. This is called the top-down calculation procedure, which will be the same with the bottom-up calculations for a stage without any feed. At the feed stage, mass and energy balances differ from a stage without feed. For the two procedures to yield similar results, the rate of enthalpy deficit at the feed stage becomes

$$
\dot{H}_{\mathrm{def}, \mathrm{F}}=\dot{Q}_{C}+\dot{D}\left(H_{D}+H_{L} \frac{\left(x_{D}-y_{F}^{*}\right)}{\left(y_{F}^{*}-x_{F}^{*}\right)}-H_{V} \frac{\left(x_{D}-x_{F}^{*}\right)}{\left(y_{F}^{*}-x_{F}^{*}\right)}\right)
$$

The values of $y_{F}^{*}$ and $x_{F}^{*}$ maybe obtained from an adiabatic flash for a single phase feed, or from the constant relative volatility estimated with the converged compositions at the feed stage and feed quality. This procedure can be reformulated for multiple feeds and side products as well as for different choices of the key components. In a CGCC, a pinch point near the feed stage occurs for nearly binary ideal mixtures. However, for nonideal multicomponent systems pinch exists in rectifying and stripping sections. 

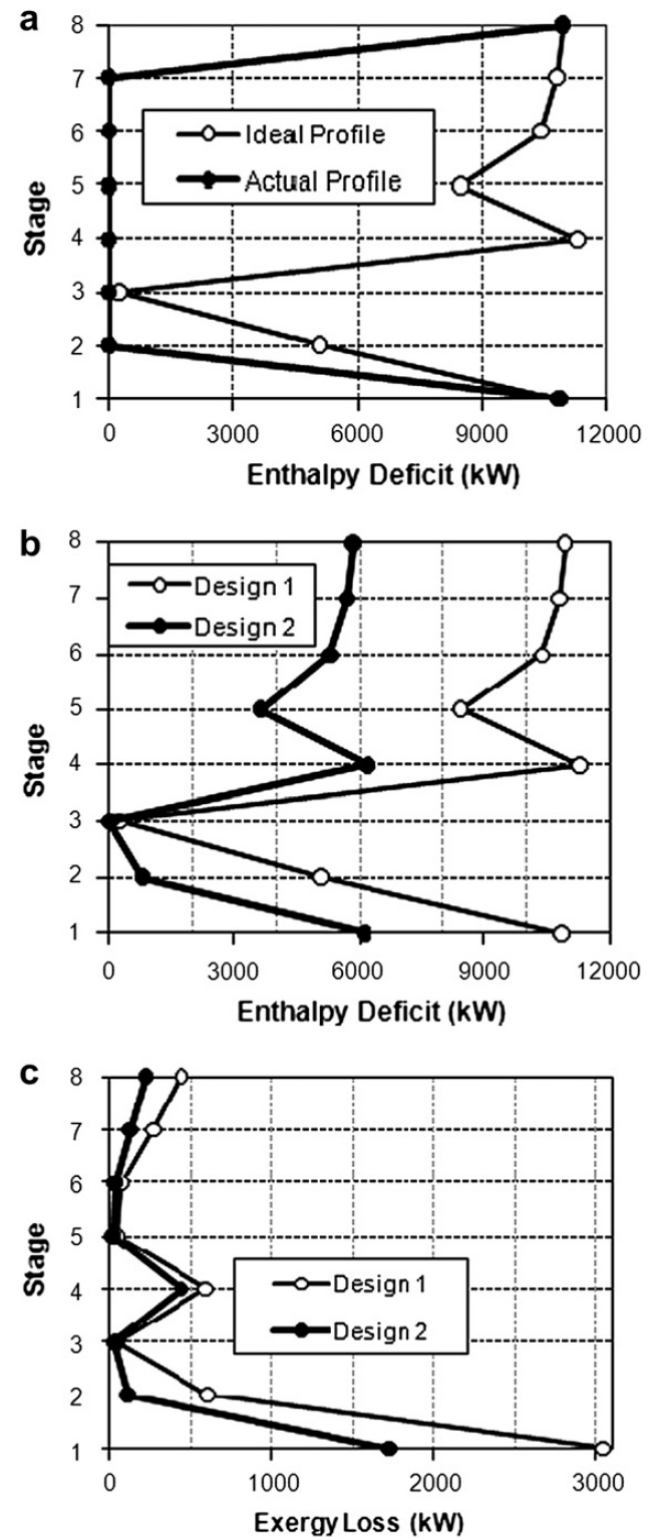

Figure 2. Column T202: (a) base case stage-enthalpy deficit curves; (b) comparison of the stage-enthalpy deficit curves of base case and retrofitted designs; (c) comparison of the stage-exergy loss profile of base case design and retrofitted designs.

A horizontal distance between the CGCC pinch point and the vertical axis represents the excessive use of heat, and therefore the scope for reduction in reflux ratio [18]. For smaller reflux ratios, the CGCC will move towards the vertical axis, and hence reduce the reboiler and condenser duties, which may be estimated by

$$
\dot{Q}_{R}-\dot{Q}_{R, \text { min }}=\dot{Q}_{C}-\dot{Q}_{C, \text { min }}=\dot{D} \lambda\left(R-\frac{\left(x_{D}-y_{F}^{*}\right)}{\left(y_{F}^{*}-x_{F}^{*}\right)}\right)
$$

where $\lambda$ is the heat of vaporization and $R$ is the reflux ratio. The horizontal distance of the CGCC from the temperature axis, however, determines the targets for installing a side reboiler or side condenser at suitable temperatures [12]. For example, a sharp change on the reboiler side may be due
Table 3

Comparison of operating conditions and configurations of designs 1 and 2 for distillation column T301.

$\begin{array}{lcc}\begin{array}{l}\text { Conditions \& } \\ \text { Configurations }\end{array} & \begin{array}{c}\text { Design 1 } \\ \text { (base case) }\end{array} & \begin{array}{c}\text { Design 2 } \\ \text { (retrofitted) }\end{array} \\ \text { No. of stages } & 5 & 5 \\ \text { Feed stage } & 3 & 3 \\ \text { Feed temperature, }{ }^{\circ} \mathrm{C} & 50 & 81.2 \\ \text { Reflux ratio } & 1.5 & 0.01 \\ \text { Condenser duty, } \mathrm{kW} & -6401.90 & -2590.48 \\ \text { Distillate rate, } \mathrm{kmol} / \mathrm{h} & 224.14 & 224.44 \\ \text { Condenser temperature, }{ }^{\circ} \mathrm{C} & 52.99 & 53.03 \\ \text { Condenser pressure, bar } & 0.40 & 0.40 \\ \text { Reboiler duty, } \mathrm{kW} & 6849.49 & 2800.34 \\ \text { Boil up rate, kmol/h } & 272.20 & 99.30 \\ \text { Bottoms rate, } \mathrm{kmol} / \mathrm{h} & 27.36 & 27.27 \\ \text { Reboiler temperature, }{ }^{\circ} \mathrm{C} & 255.24 & 267.60 \\ \text { Reboiler pressure, bar } & 0.50 & 0.50\end{array}$

to subcooled feed, and a feed preheater with a heat duty depending on the change can be installed [13]. On the other hand, a sharp change in the enthalpy represents in appropriate feed conditioning, such as feed quality or temperature. Feed conditioning is usually preferred to side condensing or reboiling, since the side heat exchangers are effective at suitable temperature levels or stages only.

\subsection{Exergy Loss Profiles}

Exergy losses represent inefficient use of available energy due to irreversibility, and should be reduced by suitable retrofits. For a steady state system, energy balance is

$\sum_{\text {out of system }}\left(\dot{n} h+\dot{Q}+\dot{W}_{s}\right)-\sum_{\text {out of sy:tem }}\left(\dot{n} h+\dot{Q}+\dot{W}_{s}\right)=0$

Exergy balance for a steady state system shows that exergy is not conserved $[16,20]$

$$
\begin{aligned}
& \sum_{\text {into system }}\left(\dot{n} e_{x}+\dot{Q}\left(1-\frac{T_{0}}{T_{S}}\right)+\dot{W}_{S}\right)-\sum_{\text {out of system }}\left(\dot{n} e_{x}+\dot{Q}\left(1-\frac{T_{0}}{T_{S}}\right)\right. \\
& \left.+\dot{W}_{S}\right)=\dot{E}_{x, \text { destroyed }}=\dot{E}_{x, \text { loss }}
\end{aligned}
$$

where $\dot{W}_{\mathrm{S}}$ is the shaft work. The total rate of exergy $\dot{E}_{x ; \text { loss }}$ represents the overall thermodynamic imperfections, and directly proportional to the rate of entropy production due to irreversibilities in a column operation. As the exergy loss increases, the net heat duty has to increase to enable the column to achieve a required separation. Consequently, smaller exergy loss means less waste heat or thermodynamic imperfections, which include pressure drop, heat and mass transfer due to finite driving forces, and mixing of flows with different compositions, temperatures, and pressures.

For distillation columns, the difference between the exergies of products and feed streams determines the minimum total exergy flow rate (separation work) necessary for a required separation

$$
\dot{E}_{x, \min }=\sum_{\text {out }} \dot{n} e_{x}-\sum_{\text {in }} \dot{n} e_{x}
$$

A conventional column receives heat at a higher temperature level in the reboiler, and discharges about the same amount in the condenser at a lower temperature. Therefore, it resembles a heat engine that produces the separation work [19]. 

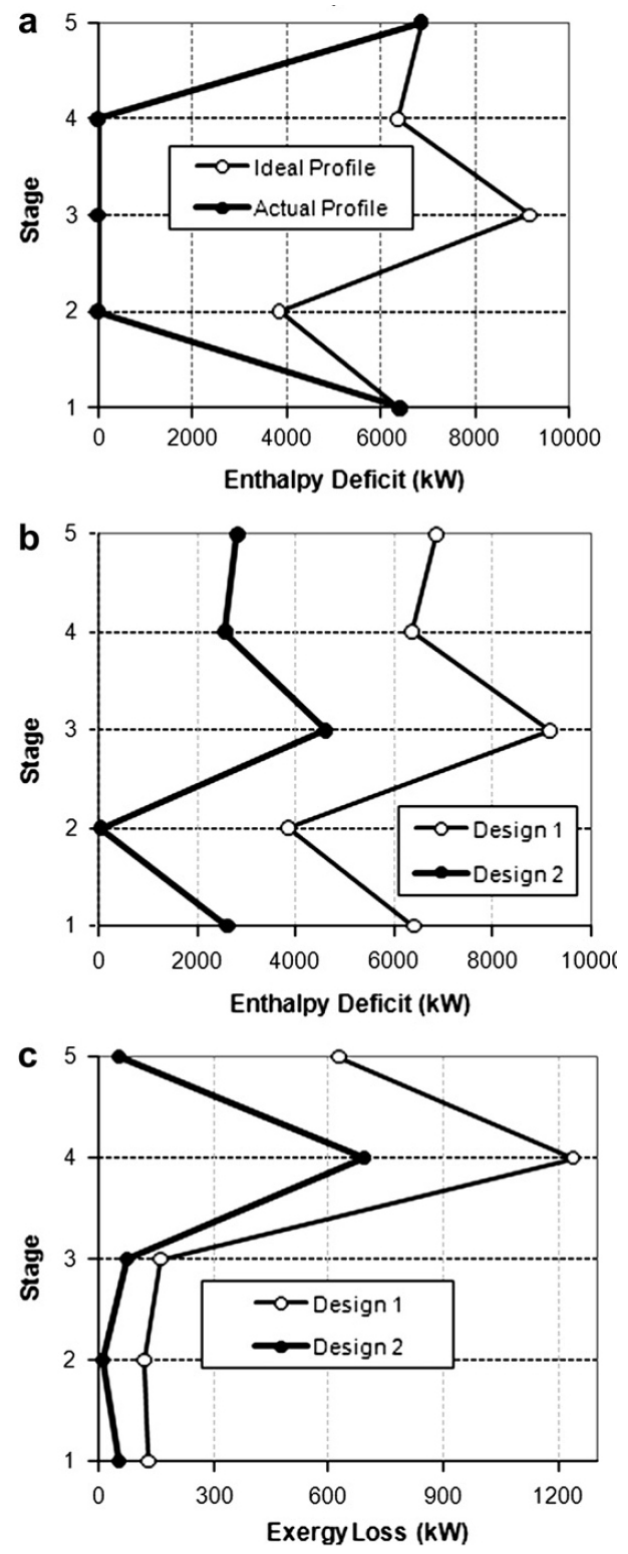

Figure 3. Column T301: (a) base case stage-enthalpy deficit curves; (b) graphical comparison of the stage-enthalpy deficit curves of base case and retrofitted designs; (c) graphical comparison of the stageexergy loss profile of base case design and retrofitted designs.

For a reversible distillation column, Carnot factors $\left(1-T_{0}=\right.$ $T$ ) in Equation (11) describe the maximum work available from a heat source.

When $\dot{E}_{x ; \min }>0$, the thermodynamic efficiency becomes

$$
\eta=\frac{\dot{E} x_{\min }}{\dot{E} x_{\text {loss }}+\dot{E} x_{\min }}
$$

The denominator in Equation (13) represents the total exergy input. Thermodynamic efficiencies before and after the retrofits can quantify the improvements, and help assessing the effectiveness of retrofits.

\subsection{Column NQ curves}

NQ curves are the plots of heat load $Q$ versus total num-
Table 4

Comparison of operating conditions and configurations of designs 1 and 2 for distillation column T302.

Conditions \& Configurations Design 1 (base case) Design 2 (retrofitted)

No. of stages 1616

Feed stage 139

Feed temperature, ${ }^{\circ} \mathrm{C} 53.053 .1$

Reflux ratio 2.001 .70

Condenser duty, kW -2663.60 -2405.65

Distillate rate, $\mathrm{kmol} / \mathrm{h} 90.9691 .17$

Condenser temperature, ${ }^{\circ} \mathrm{C} 66.7566 .83$

Condenser pressure, bar 1.101 .10

Reboiler duty, kW 2881.46 1223.18

Side reboiler stage - 11

Side reboiler duty, $\mathrm{kW}-1400$

Boil up rate, $\mathrm{kmol} / \mathrm{h} 254.61108 .04$

Bottoms rate, kmol/h 133.18133 .21

Reboiler temperature, ${ }^{\circ} \mathrm{C} 101.98101 .90$

Reboiler pressure, bar 1.101 .10

Stage 8 pressure, bar 1.101 .10

ber of stages N. NQ curves analysis in Aspen Plus calculates number of stages, reflux ratio, and optimum feed locations where a certain heat load (reboiler or condenser duty) is minimized in a distillation column [6]. These calculations do not alter the simulation results of the same column. NQ curves can be extended to plot reflux ratio as it is related to heat load and automatically generate the results of heat load and objective function to plot against number of stages. If the objective function is minimized, heat load will show a monotonic decrease with increasing number of stages. The column needs to be constrained by purity or recovery specification and must have a sufficiently large number of stages to perform NQ curves.

\subsection{Equipartition Principle}

The equipartition of forces principle combines the nonequilibrium thermodynamics approach with the CauchyLagrange optimization procedure and shows that the best trade-offs between exergy loss and transfer area in transport processes are possible when the thermodynamic driving forces are uniform over the transfer area [16,21]. Some options for achieving a thermodynamic optimum are to improve an existing design so the operation will be less irreversible and to distribute the irreversibilities uniformly over space and time [22].

\section{Biodiesel Production Plant}

Figure 1a shows a process flow diagram (PFD) of a conventional biodiesel plant [23] with a slightly modified configuration using NQ curve approach, while Figure $1 \mathrm{~b}$ shows the PFD with heat integration and retrofitted distillation columns. The biodiesel plant uses methanol, oil, water/ $\mathrm{NaOH}$ and $\mathrm{H}_{3} \mathrm{PO}_{4}$ as the basic feed streams, and produces 24,357 $\mathrm{kg} / \mathrm{h}$ and $99.4 \%$ pure of fatty acid methy lester (FAME). The by products are $99.99 \%$ pure $2510 \mathrm{~kg} / \mathrm{h}$ glycerol and $99.6 \%$ pure $2402 \mathrm{~kg} / \mathrm{h}$ water. The FAME synthesis takes place in a RStoic reactor by transesterification reaction catalyzed by $\mathrm{NaOH}$ at $60^{\circ} \mathrm{C}[1,23]$ with a by product of glycerol. The methanol/oil molar ratiois $6.14: 1$ and $95 \%$ percent oil conversion was assumed. The reactor outlet contains methanol, oil, water, $\mathrm{NaOH}$, and glycerol beside the main product of 

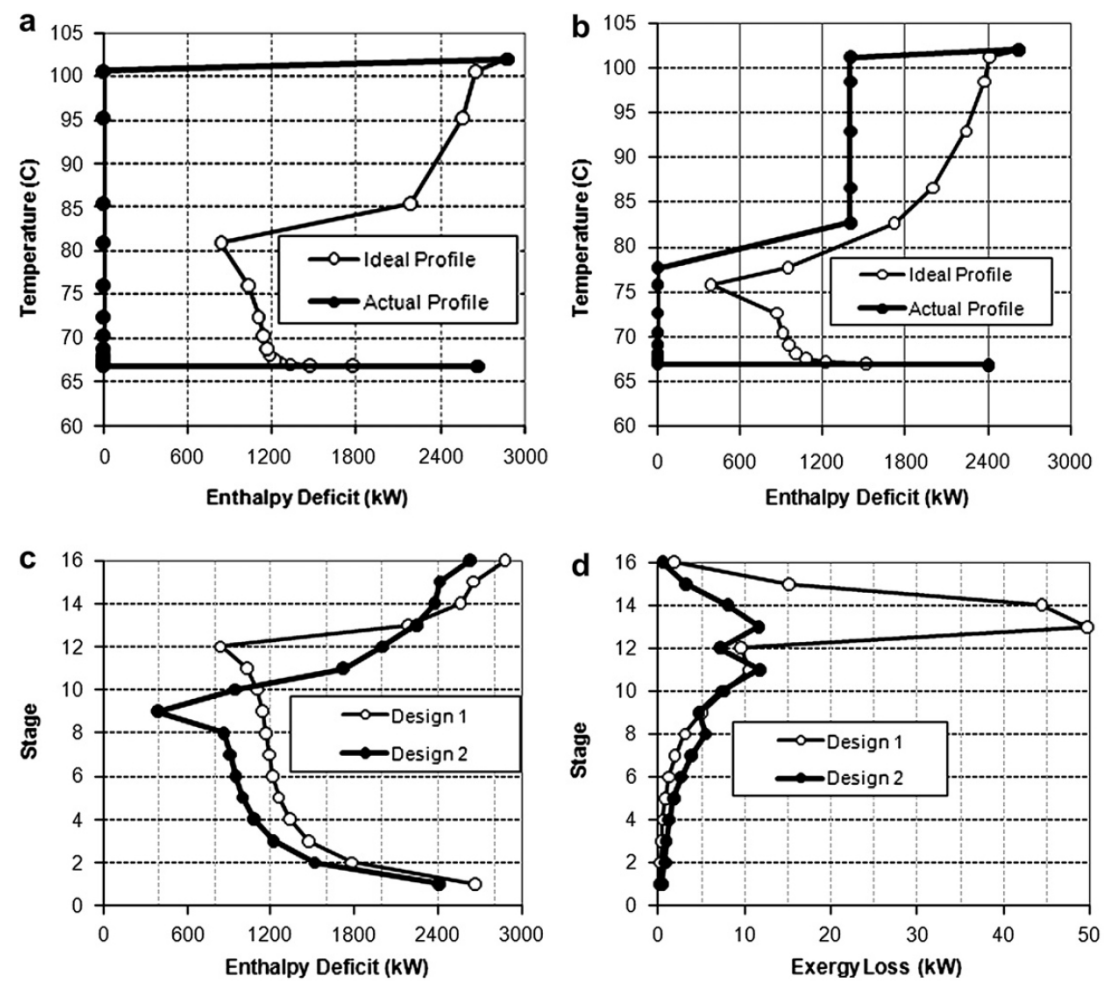

Figure 4. Column T302: (a) base case temperature-enthalpy deficit curves; (b) temperature-enthalpy deficit curves with side reboiler; (c) comparison of the stage-enthalpy deficit curves of base case and retrofitted designs; (d) comparison of the stage-exergy loss profile of base case design and retrofitted designs.

FAME. The outlet of the reactor is pumped into the extractor T201 that uses water as a solvent to partially extract polar components from the mixture. The top product is fed to distillation column T202 at stage 3 where the FAME is purified. This column operates with six stages, a partial-vaporliquid condenser and a kettle reboiler. The bottom product containing some FAME and mostly oil is recycled to the reactor. The vapor phase stream containing small amounts of water/methanol is a waste stream while the distillate is the product FAME.

The bottom flow of the extractor T201 and phosphoric acid $\left(\mathrm{H}_{3} \mathrm{PO}_{4}\right)$ are fed to the reactor R201 where acid/base neutralization reaction takes place. The reactor outlet contains mainly liquid water, methanol, and glycerol, and some solid $\mathrm{H}_{3} \mathrm{PO}_{4}$ and $\mathrm{Na}_{3} \mathrm{PO}_{4}$. Flash column F301 separates the solid waste while the liquid stream S10 is fed to stage 3 of distillation column T301 where the separation of glycerol from

Table 5

Some of the stream properties for the base case design shown in Figure $1 \mathrm{a}$.

Stream ${ }^{\dot{n}}(\mathrm{kmol} / \mathrm{h}) \dot{m}(\mathrm{~kg} / \mathrm{h}) T\left({ }^{\circ} \mathrm{C}\right) h(\mathrm{~kJ} / \mathrm{mol}) s(\mathrm{~kJ} / \mathrm{kmol}-\mathrm{K}) e_{r}(\mathrm{~kJ} / \mathrm{mol})$ S5 92.22 25795.87 59.99-686.10 -2645.79 102.74

S6 $4.41102 .9744 .01-225.87-49.85-211.00$

FAME 86.06 24356.87 44.01 -693.57-1802.44 -156.17

S7 $1.751336 .04340 .34-1298.87-50345.2313711 .56$

S10 $251.507825 .7650 .00-309.68-232.31-240.41$

S13 $224.145315 .7652 .99-265.03-184.53-210.01$

GLYCEROL $27.362510 .00255 .24-616.58-495.82-468.75$

S15 224.14 5315.76 53.04-265.02 -184.52 -210.01

WATEROUT 133.18 2403.76 101.98 -279.90 -145.46 -236.53

METHOUT 90.962912 .0066 .75 -234.62 -227.55 -166.78 methanol and water takes place.

Column T301 has five equilibrium stages with a total condenser and a kettle reboiler. The bottom product contains nearly pure glycerol while the distillate was fed to stage 13 of distillation column T302 for purification of methanol. Column T302 has 16 stages, a total condenser and a kettle reboiler. The bottom product is mainly water and the distillate methanol is recycled through mixer M101.

Table 1 shows the mass and energy balances obtained for the base case shown in Figure 1a. The thermodynamic model of UNIF-DMD is used to estimate the vapor properties in columns T202 and T301, while the activity coefficient model NRTL model is used for predicting the equilibrium and liquid properties in column T302. Both the thermodynamic models are listed within the Aspen Plus and are chosen based on the type of the feed mixture and non-ideality in the liquid and vapor phases.

Table 6

Some of the stream properties for the retrofitted design shown in Figure $1 b$.

Stream ${ }^{\dot{n}}(\mathrm{kmol} / \mathrm{h}) \dot{m}(\mathrm{~kg} / \mathrm{h}) T\left({ }^{\circ} \mathrm{C}\right) h(\mathrm{~kJ} / \mathrm{mol}) s(\mathrm{~kJ} / \mathrm{mol}-\mathrm{K}) e_{x}(\mathrm{~kJ} / \mathrm{mol})$ S5A 92.21 25795.53 59.98-686.16-2646.10 102.77

WATMET $4.41102 .9744 .08-225.89-49.71-211.06$

FAME $86.0924356 .6044 .07-693.29-1788.52-160.04$

S7A $1.711336 .00347 .12-1314.00-52207.5714251 .68$

S10A $251.757827 .0750 .00-309.70-232.17-240.48$

S13 224.44 5317.03 53.03 -265.11 -184.38 -210.14

G-OUT 27.28 2510.00 267.60 -614.13 -491.23 -467.67

S15 224.44 5317.03 53.08 -265.11 -184.37 -210.14

WATEROUT $133.262405 .03102 .00-279.90-145.45-236.54$

METHOUT $91.172912 .0066 .83-234.88$-226.94 -167.21 
Table 7

Approximate fixed capital cost calculations for the retrofits. Heat exchanger Type Duty Pressure Material Area FCC ${ }^{\mathrm{b}}$ $(\mathrm{kW})\left(\right.$ bar) $\left(\mathrm{m}^{2}\right)(\$)$

Preheater (HTX1) S/Ta Fixed 380.38 1.0 Carbon 10 73,600 T202 Tube Steel

Sheet

Preheater (HTX2) S/T Fixed 266.02 1.1 Carbon 10 73,600

T301 Tube

Sheet

Side reboiler T302 Floating 1400.00 1.1 Carbon 40 92,700

Head Steel

a S/T: Shell and tube.

b Approximate Fixed Capital Cost (FCC) with the Chemical Engineering Plant Cost Index $(\mathrm{CEPCI})=580$ [24].

\section{Results and Discussion}

\subsection{Column T202}

Table 2 shows the base case (Design 1) operating conditions and design parameters for distillation column T202, which operates with six equilibrium stages. Figure $2 \mathrm{a}$ shows the stage-enthalpy deficit curves for the base case design produced by the Aspen Plus simulator. These enthalpy deficit curves compare the cumulative heating and cooling requirements in actual and ideal operations at PNMTC. The horizontal gap between the Temperature-Enthalpy CGCC pinch points and the ordinate (temperature axis), shown in Figure $2 \mathrm{a}$, represent the scope for reduction in heat duties through decreasing reflux ratio. The reflux ratio is reduced from 1.10 to 0.19 . A sharp enthalpy changed isplayed in Figure 2a indicates the scope for adjustment on feed conditioning. For this purpose, the hot stream GLYCEROLat $267.6^{\circ} \mathrm{C}$, which is the bottom product of column T301, is used to heat the feed stream S5 from $60.0^{\circ} \mathrm{C}$ to $86.5^{\circ} \mathrm{C}$ in heat exchanger HTX1, as seen in Figure $1 \mathrm{~b}$. Because of this process heat integration within the retrofitted design, no extra hot utility is required.

Figure $2 \mathrm{~b}$ compares the CGCCs for the base case and retrofitted designs. The actual and ideal profiles are closer to each other after the retrofits. Figure 2c compares the exergy loss profiles for design 1 and design 2 . The reduction in the total exergy loss or the recovered available energy is $47.27 \%$ as the total exergy loss is reduced from $5062.70 \mathrm{~kW}$ in base case to $2669.67 \mathrm{~kW}$ in retrofitted design. Table 2 compares the base case design and retrofitted design column configurations and operating conditions. The condenser duty decreased from $10,844.19 \mathrm{~kW}$ to $6,129.29 \mathrm{~kW}$ and are boiler duty decreased from $10,948.77 \mathrm{~kW}$ to $5,840.57 \mathrm{~kW}$, and number of stages increased from 6 to 8 . Additional side reboiler or condenser is not feasible in T202 due to small number of stages.

\subsection{Column T301}

As the base case design in Table 3 shows, distillation column T301 has five stages, and a total condenser with a duty of $6401.90 \mathrm{~kW}$ and a reboiler with a duty of $6,849.49 \mathrm{~kW}$. Figure $3 \mathrm{a}$ shows the CGCCs with sharp change around feed stage, which suggests adjustment on feed conditioning. As Figure 1a shows the bottom product of column T202 is cooled in heat exchanger E301 before it is recycled. In the retrofitted design, process heat of stream S7 is integrated to preheat the feed stream S10 of column T301 from $50.0^{\circ} \mathrm{C}$ to $81.2^{\circ} \mathrm{C}$. The large horizontal gaps between the temperatureenthalpy pinch points and the ordinate shown in Figure 3a suggest reduction in reflux ratio. The minimum reflux ratio estimated from Underwood Equation is 0.00034, and the reflux ratio was reduced from 1.5 to 0.01 .

Table 3 compares the operating conditions and column configurations for the base case design and the retrofitted design of column T301. The condenser duty is reduced to 2590.48 $\mathrm{kW}$ from $6401.9 \mathrm{~kW}$, While the reboiler duty is reduced to $2800.34 \mathrm{~kW}$ from $6849.49 \mathrm{~kW}$ after retrofitting. The ideal and actual enthalpy deficit curves in Figure $3 b$ are closer in the retrofitted design compared with that of the base case design. The exergy loss profile shown in Figure $3 \mathrm{c}$ shows the reduction in exergy loss at every stage. The retrofits reduce the total exergy losses from $2277.30 \mathrm{~kW}$ design 1 to 886.82 $\mathrm{kW}$ in design 2.

\subsection{Column T302}

As Table 4 shows, base case design of distillation column T302 has 16 stages, and operates with a total condenser and with a reflux ratio of 2 . The feed is introduced on stage 13 . Aspen Plus NQ curves yield an optimum reflux ratio of 1.7 and an optimum feed stage nine with the duties of condenser and reboiler are $2663.60 \mathrm{~kW}$ and $2881.6 \mathrm{~kW}$, respectively. The feed stream S15 at temperature of $53^{\circ} \mathrm{C}$ enter column T302 at stage 13. Figure 4a shows a significant area difference between the ideal and actual temperature-enthalpy deficit profiles above the pinch, and hence suggests side reboiling at appropriate temperature levels to decrease the difference. A side reboiler at stage 11 with the duty of $1400 \mathrm{~kW}$ reduces the area between the ideal and actual enthalpy profiles considerably, as seen in Figure $4 \mathrm{~b}$. The additional reboiler would be more economical due to operation at a lower temperature and require less duty compared to the existing reboiler. With the modifications of the reflux ratio, feed stages location, and side reboiler, the total reboiler duty decreases by $8.95 \%$, from $2881.46 \mathrm{~kW}$ to $2623.63 \mathrm{~kW}$ and the efficiency increases from $42.3 \%$ to $60.5 \%$. Figure 4 c compares the enthalpy deficit curves for designs 1 and 2 .

Table 8

Assessment of the effectiveness of the retrofits: minimum exergy of separation and thermodynamic efficiency estimations based on the converged simulation.

Column Design 1 Design 2 Saved $\dot{E}_{x}(\mathrm{~kW})$ Electricity Saving (\$/year) FCC of Retrofits \$

$\dot{E}_{x ; \text { min }}(\mathrm{kW}) \dot{E}_{x ; \text { loss }}(\mathrm{kW}) \eta \% \dot{E}_{x ; \text { min }}(\mathrm{kW}) \dot{E}_{x: \text { loss }}(\mathrm{kW}) \eta \%$

T202 36.3 5062.7 0.7 39.2 2669.6 1.42393.0 1,194,887.7 73,600

T301 157.6 $2277.36 .5172 .2886 .816 .21390 .5694,294.573,600$

T302 111.3 151.8 42.3 109771.5 60.580.4 41,135.3 92,700

Total $7491.83627 .93863 .91,929,317.5239,900$

$\dot{E}_{x ; l o s s}:$ Total column exergy loss from converged simulation by Aspen Plus. FCC: Fixed capital cost. 
Figure $4 \mathrm{~d}$ compares the exergy loss profiles in design 1 and design 2 . The base case design operates with a large exergy losses at the feed stage and stage 14, while other stages have the smaller exergy losses. The retrofits reduce the total exergy losses by about $52.93 \%$, from $151.86 \mathrm{~kW}$ in design 1 to 71.48 $\mathrm{kW}$ in design 2 . This is also reflected through the more uniform exergy loss distributions in design 2, which are in line with the equipartition principle $[21,22]$. Table 4 compares the operating conditions and column configurations of designs 1 and 2. Tables 5 and 6 show the stream properties and exergy values estimated in base and retrofitted designs.

A total exergy reduction of $3863.89 \mathrm{~kW}$ was obtained in all the three retrofitted distillation columns. Table 8 presents the energy saving estimations of around \$1,929,317/year based on the unit cost of electricity of $\$ 0.060 / \mathrm{kW}$-h and a total 8322 $\mathrm{h} /$ year of the plant operation. The fixed capital costs (FCC) for the heat exchangers were estimated using CAPCOST program and the 2009 chemical engineering plant cost index of 580 [24]. FCC consists of direct and indirect cost [24]. Table 7 shows the approximate values of FCC for the heat exchangers needed for the retrofit and neglects the cost of increasing number of stages from six to eight for column T202. The overall exergy loss decreased to $3627.97 \mathrm{~kW}$ from 7491.86 $\mathrm{kW}$, which shows that the retrofits are effective and save a considerable amount of energy.

\section{Conclusions}

This study suggests a more environmentally friendly approach to design of a biodiesel production plant by using thermodynamic analysis which produces column grand composite curves and exergy loss profiles to assess an existing operation and suggest retrofits. The retrofits consist of feed preheating and reflux ratio modification for distillation columns T202 and T301, and locating optimum feed stage and side reboiling for column T302. Effectiveness of the retrofits has been assessed by the improved column grand composite curves and exergy loss profiles as well as by an approximate economical analysis. The total exergy loss for the columns is reduced from $7491.8 \mathrm{~kW}$ to $3627.9 \mathrm{~kW}$, which provides a considerable saving in the available energy losses. Process heat integration is desirable. With the increased thermodynamic efficiencies the columns operate with less thermodynamic imperfections and hence require less energy.

\section{References}

[1] Zhang, Y., M.A. Dube, D.D. McLean, M. Kates (2003). Biodiesel production from waste cooking oil: 2 . Economic assessment and sensitivity analysis. Bioresour Technol 90: 229-240.

[2] Kapilakarn, K., A. Peugtong (2007). A comparison of cost of biodiesel production from transesterification. Int Energy J 8: 1-6.

[3] Bandyopadhyay, S., R.K. Malik, U.V. Shenoy (1998). Temperature-enthalpy curve for energy targeting of distillation columns. Comput Chem Eng 22: 1,733-1,744.

[4] Demirel, Y. (2006). Retrofit of distillation columns using thermodynamic analysis. Sep Sci Technol 41: 791-817.

[5] Dhole, V.R., B. Linnhoff (1993). Distillation column targets. Comp Chem Eng 17: 549-560.

[6] Demirel, Y. (2004). Thermodynamic analysis of separation systems. Sep Sci Technol 39: 3,897-3,942.

[7] Aspen Engineering Suite (2004), www.aspentech.com.

[8] Al-Muslim, H., I. Dincer (2005). Thermodynamic analysis of crude oil distillation systems. Int J Energy Res 29: 637-655.

[9] Rivero, R., M. Garcia, J. Urquiza (2004). Simulation, exergy analysis and application of diabatic distillation to a tertiary amylmethyl ether production unit of a crude oil refinery. Energy 29: 467-489.
[10] Araújo, A.B., R.P. Brito, L.S. Vasconcelos (2007). Exergetic analysis of distillation processes-A case study. Energy 32: 1,185-1,193.

[11] Al-Muslim, H., I. Dincer, S.M. Zubair (2003). Exergy analysis of single- and two-stage crude oil distillation units. J Energy Resource Technol 125: 199-208.

[12] Agrawal, R., D.M. Herron (1998). Efficient use of an intermediate reboiler or condenser in a binary distillation. AI Ch E J 44: 1,303-1,315.

[13] Bandyopadhyay, S. (2002). Effect of feed on optimal thermodynamic performance of a distillation column. Chem Eng J 88: 175-186.

[14] Rivero, R. (2001). Exergy simulation and optimization of a diabatic and diabatic binary distillation. Energy 26: 561-593.

[15] DeKoeijer, G.M., R. Rivero (2003). Entropy production and exergy loss in experimental distillation columns. Chem Eng Sci 58: 1,587-1,597.

[16] Demirel, Y. (2007). Non-Equilibrium Thermodynamics Transport and Rate Processes in Physical, Chemical and Biological Processes. $2^{\text {nd }}$ ed. Amsterdam: Elsevier.

[17] Demirel, Y., S.I. Sandler (2004). Non-equilibrium thermodynamics in engineering and science. J Phys Chem 108: 31-43.

[18] Chang, H., W. Li, Jr. (2005). A new exergy method for process analysis and optimization. Chem Eng Sci 60: 2,771-2,784.

[19] Ognisty, T.P. (1995). Analyze distillation columns with thermodynamics. Chem Eng Prog 9: 40-46.

[20] Cengel, Y.A., M.A. Boles (2007). Thermodynamics: An Engineering Approach. $6^{\text {th }}$ ed. New York: McGraw Hill.

[21] Erik, S., K.R. Signe, M.L. Kristian (1996). Equipartition of forces: a new principle for process design and optimization. Ind Eng Chem 35: 4,147-4,153.

[22] Johannessen. E., A. Røsjorde (2007). Equipartition of entropy production as an approximation to the state of minimum entropy production in diabatic distillation. Energy 32: 467-473.

[23] Zhang, Y., M.A. Dube, D.D. McLean (2003). Biodiesel production from waste cooking oil: 1 . Process design and technological assessment. Bioresour Technol 89: 1-16.

[24] Turton, R., R.C. Bailie, W.B. Whiting, J.A. Shaeiwitz (2009). Analysis, Synthesis and Design of Chemical Processes, $3^{\text {rd }}$ ed. New Jersey: Prentice Hall.

\author{
Nomenclature \\ $\dot{D}:$ Distillate flow rate, $\mathrm{kmol} / \mathrm{h}$ \\ $e_{x}$ : Molar exergy, $\mathrm{kW} / \mathrm{kmol}$ \\ $E^{x}$ : Total Exergy, $\mathrm{kW}$ \\ $h$ : Enthalpy, kJ/kmol \\ $H$ : Total enthalpy ,kJ \\ $\dot{Q}$ : Heat flow (heat transfer rate), $\mathrm{kW}$ \\ $\dot{L}$ : Liquid flow rate, $\mathrm{kmol} / \mathrm{h}$ \\ m. Mass flow rate, $\mathrm{kg} / \mathrm{h}$ \\ ni: Molar flow rate, $\mathrm{kmol} / \mathrm{h}$ \\ $\dot{Q}$ : Condenser duty, $\mathrm{kW}$ \\ $\dot{Q}_{R}:$ Reboiler duty, $\mathrm{kW}$ \\ $R$ : Reflux ratio \\ s: Molar entropy, $\mathrm{kJ} / \mathrm{kmol} \mathrm{K}$ \\ $T$ : Temperature, $\mathrm{K}$ \\ $x$ : Liquid mole fraction \\ $y$ : Vapor mole fraction \\ $\dot{V}$ : Vapor flow rate, $\mathrm{kmol} / \mathrm{h}$ \\ $\dot{W}$ : Work, $\mathrm{kW}$ \\ Greek symbols \\ $\eta$ : Efficiency \\ $\lambda$ : Heat of vaporization, $\mathrm{kJ} / \mathrm{kmol}$ \\ Subscripts \\ def: Deficit \\ $D$ : Distillate \\ V: Vapor \\ $H$ : Heavy \\ L: Light \\ min: Minimum \\ $R$ : Reboiler \\ s: stream, shaft
}

